\title{
Prevalência de microrganismos periodontais intra e extra sulcular em crianças, adolescentes e adultos jovens
}

\section{Prevalence of periodontal pathogens in gingival sulcus and oral mucosa in children, adolescents and young adults}

\section{Camila Borges FERNANDES}

Mestranda em Periodontia - Universidade de Taubaté - UNITAU - Taubaté - SP - Brasil

\section{Davi Romeiro AQUINO}

Mestre em Periodontia - Universidade de Taubaté - UNITAU - Taubaté - SP - Brasil

Auxiliar Docente de Biologia Molecular - Universidade de Taubaté - UNITAU - Taubaté - SP - Brasil

\section{Jonas CARVALHO FILHO}

Especialista em Biologia Molecular - Universidade de Taubaté - UNITAU - Taubaté - SP - Brasil

\section{Sheila Cavalca CORTELLI}

Doutora em Biopatolgia - Faculdade de Odontologia de São José dos Campos - Universidade Estadual Paulista UNESP - São José dos Campos - SP - Brasil.

Prof. Assistente Doutor em Periodontia - Universidade de Taubaté - UNITAU - Taubaté - SP - Brasi

\section{José Roberto CORTELLI}

Doutor em Biopatologia Bucal - Universidade Estadual de Campinas - UNICAMP - Campinas - SP - Brasil

Prof. Assistente Doutor em Periodontia - Universidade de Taubaté - UNITAU - Taubaté - SP - Brasil

\begin{abstract}
Resumo
A instalação e progressão da doença periodontal estão associadas à presença de fatores de risco destacando-se entre eles determinadas espécies bacterianas. A proposta do presente estudo, do tipo transversal, foi avaliar por reação em cadeia da polimerase a prevalência de A. actinomycetemcomitans, $P$. gingivalis, $P$. intermedia, $T$. forsythensis e $C$. rectus no sulco gengival, na mucosa do dorso da língua e da bochecha em crianças, adolescentes e adultos jovens entre $2 \frac{1}{2} 2$ até 18 anos de idade. Foram realizadas associações dos periodontopatógenos com idade, sexo e condição periodontal. A condição periodontal foi estabelecida pelos índices de placa (IP), gengival (IG), profundidade de sondagem e nível de inserção clínica. Para análise dos dados foram utilizados os testes Qui-Quadrado e Exato de Fischer para a distribuição das variáveis qualitativas, $t$-Student para a variável IP; Mann-Whitney para a variável IG. Os resultados mostraram que as bactérias de maior e menor prevalência foram respectivamente $C$. rectus $(94 \%)$ e $P$. gingivalis (2\%), sendo esta última somente encontrada em sulco gengival de adolescentes e adultos jovens. A faixa etária de menor idade apresentou as mais baixas prevalências bacterianas. O sexo não interferiu na prevalência microbiana da população estudada. Observou-se uma pior condição clínica quando parâmetros periodontais estiveram associados a T. forsythensis e P. intermedia. Assim, concluímos que $C$. rectus foi a bactéria mais prevalente sendo o sítio intra-sulcular o mais favorável para a colonização bacteriana e, a pior condição clínica periodontal associou-se a $T$. forsythensis e P. intermedia.
\end{abstract}

\section{UNITERMOS}

Bactérias; grupos etários; periodonto; prevalência; sulco gengival 


\section{INTRODUÇÃO}

Uma adequada avaliação dos fatores de risco relacionados às doenças periodontais refere-se a um bom entendimento dos fatores etiológicos e da patogênese destas doenças. Diferentes estudos têm sido conduzidos no sentido de qualificar e quantificar microrganismos em sítios periodontalmente saudáveis ou doentes utilizando como ferramenta de detecção o método da reação em cadeia da polimerase (PCR) ${ }^{7}$, ${ }^{11,17}$. Este método pode detectar níveis extremamente baixos de bactérias bucais validando assim a presença microbiana nos estágios iniciais de colonização e distribuição das espécies patogênicas ${ }^{16}$. A cavidade bucal humana é naturalmente habitada por inúmeros microrganismos, sendo atualmente reconhecidas mais de 700 espécies neste habitat ${ }^{1}$. Outra característica interessante é o fato de que estes microrganismos podem colonizar não só as superfícies dentárias como também o tecido gengival, saliva, mucosas da bochecha e da língua ${ }^{10}$. A detecção destas bactérias em crianças e adolescentes pode ser também importante no sentido de avaliar, na dependência de sua frequiência, o risco individual para a ocorrência da doença periodontal no futuro ${ }^{15}$. Logo, a avaliação microbiana partindo desde a mais tenra idade pode ser fundamental no estabelecimento do perfil microbiano individual ou coletivo trazendo a oportunidade de delinear medidas preventivas terapêuticas que minimizem o desfecho doença periodontal. A partir destas questões o propósito do presente estudo foi avaliar a presença de Aggregatibacter actinomycetemcomitans (A.a), Porphyromonas gingivalis (P.g), Prevotella intermedia (P.i), Tannerella forsythensis (T.f) e Campylobacter rectus (C.r) no sulco gengival, dorso da língua e mucosa da bochecha de crianças, adolescentes e adultos jovens associando essas prevalências com parâmetros clínicos periodontais, idade e sexo.

\section{Material e método}

Foram incluídos no estudo um total de 100 indivíduos, sendo 36 crianças de $21 / 2$ a 5 anos; 33 crianças/ adolescentes de 6 a 12 anos; e 31 adolescentes/adultos jovens de 13 a 18 anos de idade. Como critério de exclusão considerou-se a utilização de antibioticoterapia seis meses antecedentes a realização dos exames clínicos e microbianos.
A condição clínica periodontal foi estabelecida por meio de parâmetros gengivais e periodontais, levando-se em consideração a faixa etária estudada. Para avaliar as condições gengivais utilizamos os índices de placa (IP) e gengival (IG), de acordo com Ainamo e Bay² (1975), na avaliação periodontal foram realizadas mensurações de profundidade de sondagem (PS) e do nível clínico de inserção (NCI) adotandose como critérios os estabelecidos pela AMERICAN ACADEMY OF PERIODONTOLOGY3 (1999) e com o auxílio de sondas periodontais milimetradas $(\mathrm{Hu}$ Friedy-PCP 11.5B).

Para a realização dos exames microbiológicos as amostras bacterianas foram obtidas de acordo com as características da faixa etária. Nas crianças de 21/2 a 5 anos, foram coletadas amostras extra-sulculares da mucosa da bochecha e dorso da língua, numa extensão de $1 \mathrm{~cm}$ e com 5 movimentos no sentido horário contando com o auxílio de swab tamponado de algodão

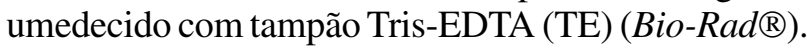
Nas crianças de 6 a 12 anos, adicionalmente as coletas bacterianas extra-sulculares, foram obtidas amostras intra-sulculares. Para a coleta intra-sulcular inicialmente o biofilme dental supra-gengival foi removido com cotonetes de algodão previamente autoclavados e, após isolamento relativo da região cones de papel também autoclavados $n^{\circ} 30$ (Dentsply ${ }^{\circledR}$ ) foram colocados no interior do sulco gengival por 60 segundos ${ }^{4}$. Para cada indivíduo um pool de amostras dos sítios mesio-vestibulares dos dentes 16, 11, 26, 36, 31 e 46 foram utilizados. Na ausência de alguns destes dentes utilizou-se os sítios mesio-vestibulares dos dentes imediatamente adjacentes. As amostras coletadas foram armazenadas em freezer a -20 graus C até o seu processamento. Para a realização da PCR utilizamos o protocolo seguido por Cortelli et al. $(2005)^{6}$.

Os IP e IG foram realizados nos mesmos dentes previamente a realização dos exames microbianos. Para os adolescentes de 13 a 18 anos, foram realizadas coletas intra e extra-sulculares como previamente descrito e avaliou-se ainda a profundidade de sondagem (PS) e nível clínico de inserção (NCI). Após a realização dos exames clínicos e microbianos os indivíduos, ou um dos seus responsáveis, receberam orientações de controle mecânico do biofilme dental com o auxílio de escovas dentais, fio e escovas unitufos e, de acordo com as necessidades individuais, receberam tratamento periodontal nas clínicas de graduação e pós-graduação do Departamento de Odontologia da UNITAU. 


\section{Resultados}

A prevalência geral, independente de idade, sexo ou local da amostra, encontrada para as bactérias foi: C. rectus (94\%), T. forsythensis (40\%), P. intermedia (23\%), A. actinomycetemcomitans (15\%), $P$. gingivalis (2\%). Este último patógeno foi encontrado apenas no sulco gengival de dois indivíduos do grupo de 13-18 anos.

Para verificar a diferença de ocorrência das bactérias entre os grupos de idades distintas, foram comparadas as distribuições de freqüência das variáveis qualitativas (bactérias) nos três grupos $\left(2 \frac{1}{2}\right.$ a cinco anos, seis a 12 anos e 13 a 18 anos).
Realizando-se uma análise comparativa das freqüências bacterianas entre amostras intra-sulculares e extra-sulculares (língua e mucosa da bochecha, juntos), na Tabela 2 , encontrou-se $P$. intermedia $(p=0,0054)$ e T. forsythensis $(p<0,001)$, mais prevalentes no sulco gengival de crianças de seis a 12 anos. No grupo de adolescentes e adultos jovens, além das duas bactérias acima citadas, $C$. rectus também apresentou maior prevalência no sulco gengival $(p=0,030)$ em relação às amostras extra-sulculres.

Realizou-se também uma comparação levando em consideração o sítio em que foi extraída cada amostra. Os gráficos 1 e 2 representam os resultados que apresentaram diferença estatística.

Tabela 1 - Comparação dos grupos etários em relação à freqüência das bactérias em sítios extra e intra-sulculares

\begin{tabular}{|c|c|c|c|c|c|c|}
\hline & & & \multicolumn{3}{|c|}{ Faixa Etária } & \multirow{2}{*}{ Total } \\
\hline & & & $2^{1 / 2-5}$ anos & $6-12$ anos & $13-18$ anos & \\
\hline \multirow{4}{*}{ C.r } & \multirow{2}{*}{ Não } & $\mathrm{N}$ & 5 & 1 & 0 & 6 \\
\hline & & $\%$ & $13,9 \%$ & $3,0 \%$ &, $0 \%$ & $6,0 \%$ \\
\hline & \multirow{2}{*}{ Sim } & $\mathrm{N}$ & 31 & 32 & 31 & 94 \\
\hline & & $\%$ & $86,1 \%$ & $97,0 \%$ & $100,0 \%$ & $94,0 \%$ \\
\hline \multirow{4}{*}{ P.g } & \multirow{2}{*}{ Não } & $\mathrm{N}$ & 36 & 33 & 29 & 98 \\
\hline & & $\%$ & $100,0 \%$ & $100,0 \%$ & $93,5 \%$ & $98,0 \%$ \\
\hline & \multirow{2}{*}{ Sim } & $\mathrm{N}$ & 0 & 0 & 2 & 2 \\
\hline & & $\%$ &, $0 \%$ &, $0 \%$ & $6,5 \%$ & $2,0 \%$ \\
\hline \multirow{4}{*}{ A.a } & & $\mathrm{N}$ & 34 & 28 & 23 & 85 \\
\hline & & $\%$ & $94,4 \%$ & $84,8 \%$ & $74,2 \%$ & $85,0 \%$ \\
\hline & & $\mathrm{N}$ & 2 & 5 & 8 & 15 \\
\hline & & $\%$ & $5,6 \%$ & $15,2 \%$ & $25,8 \%$ & $15,0 \%$ \\
\hline \multirow{4}{*}{ P.i } & & $\mathrm{N}$ & 34 & 18 & 25 & 77 \\
\hline & & $\%$ & $94,4 \%$ & $54,5 \%$ & $80,6 \%$ & $77,0 \%$ \\
\hline & & $\mathrm{N}$ & 2 & 15 & 6 & 23 \\
\hline & & $\%$ & $5,6 \%$ & $45,5 \%$ & $19,4 \%$ & $23,0 \%$ \\
\hline \multirow{4}{*}{ T.f } & & $\mathrm{N}$ & 31 & 12 & 17 & 60 \\
\hline & & $\%$ & $86,1 \%$ & $36,4 \%$ & $54,8 \%$ & $60,0 \%$ \\
\hline & & $\mathrm{N}$ & 5 & 21 & 14 & 40 \\
\hline & & $\%$ & $13,9 \%$ & $63,6 \%$ & $45,2 \%$ & $40,0 \%$ \\
\hline
\end{tabular}


Fernandes CB, Aquino DR, Carvalho Filho J, Cortelli SC, Cortelli JR

PREVALÊNCIA DE MICRORGANISMOS PERIODONTAIS INTRA E EXTRA SULCULAR EM CRIANÇAS, ADOLESCENTES E ADULTOS JOVENS

Tabela 2- Distribuição de freqüência das bactérias, no sulco (S) e na língua/mucosa (L/M), 6-12 anos e 13-18 anos

\begin{tabular}{|c|c|c|c|c|c|c|c|}
\hline & & $\begin{array}{c}\text { 6-12 anos } \\
\text { Não }\end{array}$ & $\begin{array}{c}\text { 6-12 anos } \\
\text { Sim }\end{array}$ & $\begin{array}{c}\text { 6-12 anos } \\
\text { Total }\end{array}$ & $\begin{array}{c}\text { 13-18 anos } \\
\text { Não }\end{array}$ & $\begin{array}{c}\text { 13-18 anos } \\
\text { Sim }\end{array}$ & $\begin{array}{c}\text { 13-18 anos } \\
\text { Total }\end{array}$ \\
\hline \multirow{2}{*}{ C.r S } & $\mathrm{N}$ & 2 & 31 & 1 & 30 & 31 & 33 \\
\hline & $\%$ & $6,1 \%$ & $93,9 \%$ & $3,2 \%$ & $96,8 \% *$ & $100,0 \%$ & $100,0 \%$ \\
\hline \multirow{2}{*}{ C.r L/M } & $\mathrm{N}$ & 2 & 31 & 4 & 27 & 31 & 33 \\
\hline & $\%$ & $6,1 \%$ & $93,9 \%$ & $12,9 \%$ & $87,1 \%$ & $100,0 \%$ & $100,0 \%$ \\
\hline \multirow{2}{*}{ P.g S } & $\mathrm{N}$ & 33 & & 29 & 2 & 31 & 33 \\
\hline & $\%$ & $100,0 \%$ & & $93,5 \%$ & $6,5 \%$ & $100,0 \%$ & $100,0 \%$ \\
\hline \multirow{2}{*}{ P.g L/M } & $\mathrm{N}$ & 33 & & 31 & & 31 & 33 \\
\hline & $\%$ & $100,0 \%$ & & $100,0 \%$ & & $100,0 \%$ & $100,0 \%$ \\
\hline \multirow{2}{*}{ A.a S } & $\mathrm{N}$ & 29 & 4 & 27 & 4 & 31 & 33 \\
\hline & $\%$ & $87,9 \%$ & $12,1 \%$ & $87,1 \%$ & $12,9 \%$ & $100,0 \%$ & $100,0 \%$ \\
\hline \multirow{2}{*}{ A.a L/M } & $\mathrm{N}$ & 30 & 3 & 26 & 5 & 31 & 33 \\
\hline & $\%$ & $90,9 \%$ & $9,1 \%$ & $83,9 \%$ & $16,1 \%$ & $100,0 \%$ & $100,0 \%$ \\
\hline \multirow{2}{*}{ P.i S } & $\mathrm{N}$ & 20 & 13 & 25 & 6 & 31 & 33 \\
\hline & $\%$ & $60,6 \%$ & $39,4 \%$ * & $80,6 \%$ & $19,4 \%$ * & $100,0 \%$ & $100,0 \%$ \\
\hline \multirow{2}{*}{ P.i L/M } & $\mathrm{N}$ & 26 & 7 & 27 & 4 & 31 & 33 \\
\hline & $\%$ & $78,8 \%$ & $21,2 \%$ & $87,1 \%$ & $12,9 \%$ & $100,0 \%$ & $100,0 \%$ \\
\hline \multirow{2}{*}{ T.f S } & $\mathrm{N}$ & 12 & 21 & 21 & 10 & 31 & 33 \\
\hline & $\%$ & $36,4 \%$ & $63,6 \%$ * & $67,7 \%$ & $32,3 \%$ * & $100,0 \%$ & $100,0 \%$ \\
\hline \multirow{2}{*}{ T.f L/M } & $N$ & 27 & 6 & 25 & 6 & 31 & 33 \\
\hline & $\%$ & $81,8 \%$ & $18,2 \%$ & $80,6 \%$ & $19,4 \%$ & $100,0 \%$ & $100,0 \%$ \\
\hline
\end{tabular}

$\overline{{ }^{*} \mathrm{p}<0,05}$

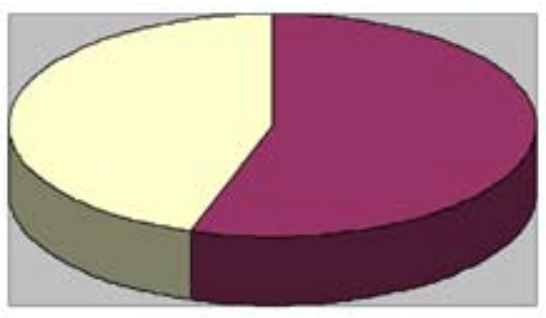

*p-valor = 0,017 (teste Qui-Quadrado)

Gráfico 2: Comparação dos grupos em relação à C.r na língua

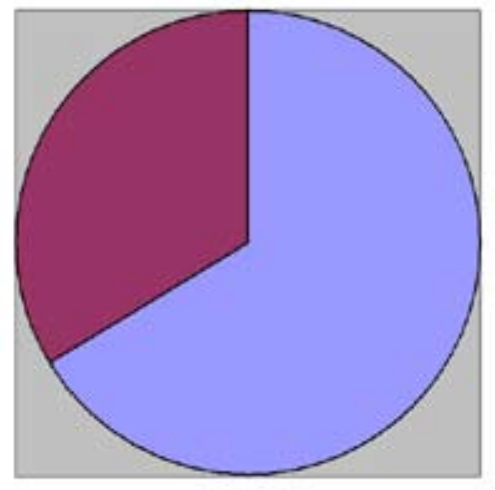

p-valor = 0,012 (teste Qui-Quadrado) 
Tabela 3 - Resultado da comparação dos IP e IG

\begin{tabular}{ccccccccc}
\hline Índices & Faixa Etária & $\mathbf{N}$ & Média & Mediana & $\begin{array}{c}\text { Desvio } \\
\text { Padrão }\end{array}$ & Mínimo & Máximo & p-valor \\
\hline \hline \multirow{4}{*}{ IP } & $6-12$ anos & 31 & 0,43 & 0,45 & 0,20 & 0,04 & 1,00 & \\
& $13-18$ anos & 28 & 0,54 & 0,57 & 0,28 & 0,00 & 1,00 & 0,088 \\
& Total & 59 & 0,49 & 0,49 & 0,25 & 0,00 & 1,00 & \\
\hline \multirow{4}{*}{ IG } & $6-12$ anos & 31 & 0,03 & 0,02 & 0,05 & 0,00 & 0,27 & \\
& $13-18$ anos & 28 & 0,23 & 0,13 & 0,27 & 0,00 & 1,00 & $<0,001^{*}$ \\
& Total & 59 & 0,13 & 0,04 & 0,22 & 0,00 & 1,00 & \\
\hline \hline
\end{tabular}

* estatisticamente significante $(p<0,05)$

Foram comparados também os valores das variáveis IP e IG entre os grupos de idades de seis a 12 anos e 13 a 18 anos.

Comparando-se os valores das variáveis quantitativas PS, NCI, IP e IG entre os adolescentes e adultos jovens com e sem a presença das espécies bacterianas abordadas neste estudo, com o objetivo de verificar se apresentam valores maiores ou menores destas variáveis, encontramos que:

- adolescentes e adultos jovens com P. intermedia no sulco gengival apresentaram valores mais elevados de IG $(p=0,006)$;

- a mesma população, portando de $P$. intermedia na língua, apresentou maiores valores de PS $(p=0,005)$, IP $(p=0,045)$ e IG $(p=0,002)$;

- adolescentes e adultos jovens, portadores de $T$. forsythensis no sulco gengival, apresentaram valores mais elevados de PS $(p=0,001), \mathrm{NCI}$ $(p=0,016)$ e IG $(p=0,008)$;

- a mesma população com T. forsythensis na língua, apresentou maiores valores de IG $(p=0,049)$.

Por último foi realizada uma análise de correlação entre as variáveis PS e NCI, com um diagrama de dispersão, que significa o cruzamento das duas variáveis.

Observou-se uma correlação positiva significativa entre as medidas de PS e NCI (c.c $=0,836)$, ou seja, quanto maior o valor de PS maior o valor de NCI.

\section{Dıscussão}

A identificação microbiana de diferentes espécies na cavidade bucal pode caracterizar uma ferramenta importante na avaliação de risco que os indivíduos têm em desenvolver patologias periodontais, assim, este estudo avaliou a presença de diferentes microrganismos reconhecidamente periodonto patógenos, em sítios distintos e em diferentes faixas etárias

No presente estudo $C$. rectus apresentou a maior prevalência geral, sendo também encontrada em altas frequiências por outros investigadores ${ }^{4,8}{ }^{8}$; ; podendo ser considerada membro da microbiota endógena que ocasionalmente pode contribuir para o desenvolvimento da periodontite.

O patógeno de menor prevalência, independente do sítio, idade ou sexo, foi $P$. gingivalis, o mesmo foi observado em outros estudos na literatura ${ }^{12,14}$. A baixa frequiência em que foi encontrada esta bactéria confirma que este patógeno se relaciona diretamente com indivíduos adultos portadores de periodontite crônica.

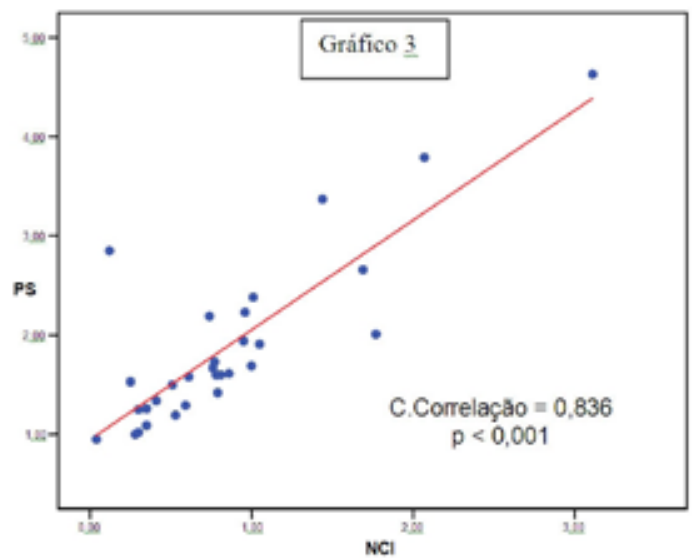

Gráfico 3: Diagrama de dispersão das vaiáveis PS e NCI 
A maior prevalência de A. actinomycetemcomitans em relação à $P$. gingivalis confirma os achados de Socransky et al. ${ }^{13}$, em que se verificou que $A$. $a c$ tinomycetemcomitans é um importante colonizador primário do complexo verde quando da avaliação da formação inicial do biofilme dental.

$O$ fato da bactéria $P$. gingivalis ter sido identificada apenas em adolescentes se assemelha ao encontrado por Tamura et al. ${ }^{14}$, existindo uma significante correlação entre idade e detecção de $P$. gingivalis, indicando que adolescentes mais que crianças jovens, deveriam ser cuidadosamente examinados o mais precocemente possível para prevenir a periodontite. Achados semelhantes aos de Lamell et al. ${ }^{9}$ que, através de regressão logística, encontraram relação positiva entre aumento da idade e colonização persistente com $P$. gingivalis.

As maiores médias de frequiência de bactérias foram encontradas no segmento etário de seis a 12 anos (Tabela 1). Estes achados coincidem com o estudo de Umeda et al. ${ }^{16}$, no qual bactérias periodontopatogênicas, exceto $C$. rectus, foram detectadas mais freqüentemente na dentição mista que na dentição decídua. As taxas de detecção de A. actinomycetemcomitans parecem aumentar no final da infância aproximando-se da adolescência, atingindo seu pico aos 12 anos $^{17}$.

Quando se comparou a distribuição das freqüências bacterianas das amostras intra-sulculares com amostras extra-sulculares, Tanaka et al. ${ }^{15}$, realizando o mesmo tipo de análise, também se encontrou diferença estatística significante ao avaliar $P$. gingivalis e $P$. intermedia no sulco em relação à língua/mucosa da bochecha, em indivíduos de três a 17 anos. Isto confere ao sulco gengival um sítio favorável à colonização bacteriana.

Fazendo uma análise comparativa das bactérias entre os três grupos de idades nos diferentes sítios, foi possível observar que $C$. rectus foi estatisticamente mais prevalente na língua de crianças de seis a 12 anos que em crianças de $2 \frac{1}{2}$ a cinco anos (Gráfico 1), possivelmente esta prevalência aumentada foi observada na população com maior idade por uma maior chance de exposição à bactéria. $T$. forsythensis apresentou maior prevalência, $\mathrm{p}=0,012$, no sulco gengival de crianças com idade de seis a 12 anos que em adolescentes de 13 a 18 anos (Gráfico 2). Semelhantemente, Umeda et al. ${ }^{16} \mathrm{em}$ um estudo comparando amostras coletadas de crianças com dentição decídua, mista e permanente, indicaram que a frequiência de detecção de $T$. forsythensis na dentição mista foi comparativamente mais alta que em relação às outras dentições. Ainda segundo estes autores, a má higiene bucal na fase de troca de dentição pode explicar a detecção de altas freqüências de bactérias periodontopatogênicas ${ }^{16}$. Durante a dentição mista, o aumento da inflamação gengival resultante da higiene bucal deficiente, pode ocasionar formação de falsas bolsas, o que pode contribuir para a colonização de patógenos periodontais e funcionar como reservatório bacteriano. Com isso, exames e cuidados profissionais neste período de transição de dentição decídua para permanente podem ser importantes para a prevenção de infecções por bactérias periodontais.

Ao se comparar as prevalências bacterianas entre os sexos, independentemente da idade ou sítio de coleta das amostras, não houve diferença estatística. $\mathrm{O}$ mesmo achado foi observado ao se comparar as freqüências bacterianas entre os sexos nos diferentes sítios bucais, ou entre as faixas etárias distintas. Resultado semelhante foi constatado por outros autores, em que não foi encontrada associação entre sexo e presença do microrganismo $A$. actinomycetemcomitans $s^{5,6,17}$. Lamell et al. ${ }^{9}$ também não observaram relação entre sexo e colonização de A. actinomycetemcomitans e $P$. gingivalis, em crianças.

Comparando-se os índices de placa e gengival entre os dois grupos etários em que estes parâmetros foram avaliados, encontrou-se que o índice gengival aumentou com o avanço da idade (Tabela 3). Nossos resultados confirmaram estudos que encontraram maiores valores médios de sangramento gengival em dentição permanente que em dentição decídua ou mista ${ }^{16,17}$.

No grupo de 13 a 18 anos, indivíduos que apresentaram $P$. intermedia no sulco ou em outro sítio, apresentaram também maiores valores, com diferença estatisticamente significante, no índice gengival, semelhante ao observado por Tanaka et al. ${ }^{15}$. Ainda nesta faixa etária, indivíduos que apresentaram $T$. forsythensis no sulco gengival demonstraram valores mais elevados de sangramento, profundidade de sondagem, e nível de inserção clínica; e a presença desta bactéria na língua implicou em maiores valores no índice gengival. Adolescentes com a presença de $P$. intermedia na língua também apresentaram uma diferença estatística nos valores de índice de placa, índice gengival e profundidade de sondagem.

Outro resultado importante observado no presente estudo de acordo com o Gráfico 3 foi a correlação positiva entre profundidade de sondagem e perda de inserção clínica na faixa etária de 13 a 18 anos de idade. Esta constatação caracteriza a tendência de que estes dois parâmetros clínicos periodontais associados reflitam o desfecho (doença periodontal) e severidade (extensão do dano causado). 


\section{Conclusões}

Após a realização do presente estudo e, de acordo com as limitações pertinentes ao desenho epidemiológico aqui traçado, podemos concluir que:

- as bactérias que apresentaram maior e menor prevalência foram $C$. rectus e $P$. gingivalis, respectivamente, concordando com o perfil microbiológico do periodonto saudável da população jovem, por nós analisada. Adicionalmente, as maiores prevalências bacterianas foram encontradas nos sítios intra-sulculares quando comparados aos extra-sulculares, sugerindo que o sulco gengival representa o ambiente mais favorável à colonização bacteriana;

- a faixa etária de $2 \frac{1}{2}$ a cinco anos apresentou as menores prevalências bacterianas;

- o grupo de 13 a 18 anos apresentou maior índice de sangramento gengival, enquanto o índice de placa foi semelhante entre indivíduos de seis a 12 e 13 a 18 anos de idade;

- o sexo não interferiu na prevalência microbiana da população estudada;

- Observou-se uma pior condição clínica quando parâmetros periodontais estiveram associados a $T$. forsythensis e $P$. intermedia.

\begin{abstract}
The onset and progression of periodontal disease are associated with risk factors involving certain bacterial species. The aim of the present transversal study was to assess, by polymerase chain reaction, the prevalence of A. actinomycetemcomitans, $P$. gingivalis, $P$. intermedia, T. forsythensis and C. rectus in the gingival sulcus, mucosa of the tongue dorsum and cheeks in children, adolescents and young adults between the ages of $2 \frac{1}{2}$ and 18 years. Associations of periodontal pathogens with age, gender and periodontal condition were made. Periodontal status was established by plaque index (PI), gingival index (GI), probing depth and clinical attachment level. The data were analyzed using the Chi-Square and Exact Fisher's test for the distribution of qualitative variables, t-Student for analyses of PI, Mann-Whitney tests for analyses of GI. The results showed that the bacteria with highest and lowest prevalence were $C$. rectus $(94 \%)$ and $P$. gingivalis (2\%) respectively, the latter being found only in the gingival sulcus of adolescents and young adults. The lowest age group presented the lowest bacterial prevalence. Gender did not interfere in the microbial prevalence of the studied population. A worse clinical condition was observed when the periodontal parameters were associated with $T$. forsythensis and $P$. intermedia. Therefore, it was concluded that $C$. rectus was the most prevalent bacteria, and that the intra sulcular site was the most favorable for bacterial colonization, and the worst periodontal clinical condition was associated with T. forsythensis and P. intermedia.
\end{abstract}

\title{
UNITERMS
}

Bacteria; age groups; periodontium; prevalence; gingival sulcus

\section{REFERÊNCIAS}

1. Aas JA, Paster BJ, Stokes LN, Olsen I, Dewhirst FE. Defining the normal bacterial flora of the oral cavity. J. Clin. Microbial. 2005 Nov.;43(4):229-35.

2. Ainamo J, Bay I. Problems and proposals for recording gingivitis and plaque. Int. Dent. J. 1975 dec.; 25(4):229-35.

3. American Academy of Periodontology. International Workshop for a classification of periodontal diseases and conditions. Ann. Periodontol. 1999 Jan.;4(1):1-6

4. Avila-Campos MJ, Velásquez-Meléndez G. Prevalence of putative periodontopathogens from periodontal patients and healthy subjects in São Paulo, SP, Brazil. Rev. Inst. Med. Trop. 2002 Jan./Feb.; 44(1):1-5.
5. Cortelli JR, Cortelli SC, Pallos D, Jorge AOC. Presença de A. actinomycetemcomitans em indivíduos com periodontite agressiva localizada ou generalizada ou periodontite incipiente. RPG - Rev Pós Grad. 2002 Abr./Jun,; 9(2):103-108.

6. Cortelli JR , Cortelli SC, Jordan S, Haraszthy VI, Zambon JJ. Prevalence of periodontal pathogens in Brazilians with aggressive or chronic periodontitis. J. Clin. Periodontol. 2005 Aug.;32(8):860-66.

7. Doungudomdacha S, Rawlinson A, Walsh TF, Douglas CW. I Effect of non-surgical periodontal treatment on clinical parameters and the number of Porphyromonas gingivalis, Prevotella intermedia and Actinobacillus actinomycetemcomitans at adult periodontitis sites. J. Clin. Periodontol. 2001 May; 28(5):437-45. 
8. Hayashi F, Okada M, Soda Y, Miura K, Kozai K. Subgingival distribution of Campylobacter rectus and Tannerella forsythensis in healthy children with primary dentition. Arch. Oral Biol. 2006 Jan; 51(1):10-14.

9. Lamell CW, Griffen AL, Mcclellan DL, Leys EJ. Acquisition and colonization stability of Actinobacillus actinomycetemcomitans and Porphyromonas gingivalis in children. J. Clin. Microbiol. 2000 Mar.; 38(3):1196-99.

10. Mager DL, Ximenez-Fyvie LA, Haffajee AD, Socransky SS. Distribution of selected bacterial species on intraoral surfaces. J. Clin. Periodontol. 2003 July; 30(7):644-54.

11. Miura M, Hamachi T, Fujise O, Maeda K. The prevalence and pathogenic differences of Porphyromonas gingivalis fimA genotypes in patients with aggressive periodontitis. J. Periodontol. Res. 2005 Apr.; 40 (2):147-52.

12. Okada MH, Hayashi F, Nagasaka N. Detection of A. actinomycetemcomitans and $\mathrm{P}$. gingivalis in dental plaque samples from children 2 to 12 years of age. J. Clin. Periodontol. 2000 Oct; 27(10):763-68.

13. Socransky SS, Haffajee AD, Cugini MA, Smith C, Kent Jr RL. Microbial complexes in subgingival plaque. J. Clin. Periodontol. 1998 Feb.;25(2):134-44.

14. Tamura K, Nakano K, Nomura R, Miyake S, Nakagawa I, Amano A et al. Distribution of Porphyromonas gingivalis fimA genotypes in Japanese children and adolescents. J. Periodontol. 2005 May ; 76(5)674-79.

15. Tanaka S, Minami M, Murakami Y, Ogiwara T, Seto K, Shoji M et al. The detection of Porphyromonas gingivalis, Prevotella intermedia and Actinobacillus actinomycetemcomitans in tooth, tongue and buccal mucosa plaques in children, using immunoslot blot assay (IBA). J. Clin. Pediatr. Dent. 2006;30(3):251-56.

16. Umeda M, Miwa Z, Takeuchi Y, Ishizuka M, Huang Y, Noguchi K et al. The distribution of periodontopathic bacteria among Japanese children and their parents. J. Periodont. Res. 2004 Dec.; 39(6):398-404.

17. Yuan K, Hsu PC, Tseng CC, Kiang D, Wang JR. Detection rate of Actinobacillus actinomycetemcomitans on the permanent $1^{\text {st }}$ molars of primary school children in Taiwan by polymerase chain reaction. J. Clin. Periodontol. 2001 Apr.; 28(4):348-52.

Recebido em: 20/06/07 Aprovado em: 23/08/07

Camila Borges Fernandes Rua Silva Jardim, no. 219, apto. 34-B, Centro, Taubaté-SP, cep. 12030-090 Tel.: (11) 9313-5199/(12) 9171-3540, (12) 8136-4553, e-mail: camborges@yahoo.com.br Autora Correspondente 